\title{
2-Fluorofucose-containing SGN-2FF
}

National Cancer Institute

\section{Source}

National Cancer Institute. 2-Fluorofucose-containing SGN-2FF. NCI Thesaurus. Code C131289.

An orally bioavailable fluorinated analog of fucose that is a protein fucosylation inhibitor, with potential antineoplastic and immunomodulating activities. Upon administration of SGN-2FF, 2-fluorofucose (2-FF) mimics fucose and is converted to guanosine diphosphate (GDP)-2FF, which prevents the formation of the fucosylation substrate GDPfucose, and the incorporation of fucose into glycoproteins by fucosyltransferase. As fucosylation of glycoproteins plays a key role in many biological processes, such as protein function, receptor binding, cell signaling and cellular adhesion, and is essential for tumor progression, blocking fucosylation decreases tumor cell growth. In addition, blocking fucosylation of monoclonal antibodies generates fucose-deficient antibodies that exert enhanced antibody-dependent cell-mediated cytotoxicity (ADCC). 